\title{
Words Versus Pictures: Leveraging the Research on Visual Communication
}

\author{
Pauline Dewan \\ Reference Librarian \\ Wilfrid Laurier University \\ pdewan@wlu.ca
}

\section{Abstract}

Librarians, like many professionals in other occupations, tend to rely on text and underutilize graphics. Research on visual communication shows that pictures have a number of advantages over words. We can interact more effectively with colleagues and patrons by incorporating ideas from this body of research.

\section{Keywords}

visual communication; visual literacy; multimedia literacy; pictures; graphics; images

\section{Introduction}

If information is our currency, transmitting it effectively to users and colleagues is critical to our success. Although we communicate in a variety of ways on a host of different platforms, our favourite way to do so is via the written word. After all, we are the keeper of the word and our brand (at least according to our users) is books (OCLC). Literacy is one of our deeply held values. Librarians, like the population at large, have a subtle bias against pictures. We tend to think of them as a slightly inferior form of communication. After all, children develop intellectually by moving from picture books to chapter books, and then to books filled with even more words. And we certainly esteem readers more than we do television viewers. We shake our heads when we see pictures, images, and videos creeping into our culture and replacing words.

\section{Our Pictorial Roots}

After centuries of predominantly textual communication, the picture gained momentum in the mid-nineteenth century with the development of technological innovations such as the daguerreotype process (Davies, Bathurst, and Bathurst 32). In the twentieth and twenty-first centuries, mass-produced cameras, televisions, computers, videocameras, the internet, and mobile devices have facilitated the use of graphics in all forms of communication. And during the last three decades in particular, screens have come to dominate our lives. The average American household contains more televisions than people, and every minute of the day, forty-eight hours of videos is uploaded to YouTube (Apkon 8, 23). Yet, this shift in balance between the picture and the word is nothing new; we are actually returning to our pictorial roots. Humans have used pictures to record their experiences for 250 centuries, pictograms and ideograms for the next 20 
centuries, and words for the remaining 15 centuries (Davies, Bathurst, and Bathurst 2). Communicating visually is what we have done for the vast majority of human history. And as Brown points out, "We are neurologically wired with an overwhelmingly visual sensory ability" (222).

\section{The Benefits of Pictures}

By taking advantage of what communication experts have discovered about the benefits of the visual medium, and incorporating graphic elements into our largely text-driven communications, we can communicate more effectively.

Pictures are not only more effortless to recognize and process than words, but also easier to recall. When words enter long-term memory they do so with a single code. Pictures, on the other hand, contain two codes: one visual and the other verbal, each stored in different places in the brain (Paivio). The dual-coding nature of images allows for two independent ways of accessing visual memories, increasing the odds of remembering at least one of them. But not all images are created equal. Research has shown that we do not remember decorative images as well as we do informative ones (Harp and Meyer). And just as we recall pictures better than concrete words, we also remember concrete words better than abstract ones (Reed 48). If we really want others to remember something, we should use words and pictures together. Because we store visual and verbal memories separately, we have the best recall when we are able to access one or the other (Kosslyn).

Adding illustrations to text, researchers have concluded, aids comprehension and learning. Levie and Lentz reviewed 155 studies on the effects of text illustration and found that they increased understanding in 98 percent of the experiments. Pictures facilitate learning by providing clarifying examples, extra-lingual information, contexts for interpretation, and redundancy which aids recall. Words, they conclude, "are not the only road to wisdom" (226).

Communicating with both graphics and text is well suited to the way our minds work. Reed points out that "our cognitive abilities to comprehend, remember, reason, solve problems, and make decisions depend on a rich combination of words and images" (13). Language itself rests on a foundation of visual thinking, and metaphoric language in particular is inextricably linked with visual images. Metaphors underlie abstract thinking "by mapping them onto concrete ideas" (Reed 35). In the unconscious mind, the verbal and the visual are also inextricably linked (Seppäanen). If we have different ways of communicating, it makes little sense to rely on only one (Brown).

\section{Improving Communication}

The information literacy standards for higher education are an example of the way librarians are reconsidering visual communication and visual learning. ACRL's "Visual Literacy Competency Standards for Higher Education" acknowledges the importance of images and media in a highly visual society. Imagery, the committee points out, "is no longer supplemental to other forms of information." 
Academic librarians are currently rewriting the main ACRL standards to expand the concept of information literacy beyond textual proficiency. The new standards will incorporate visual and multimedia literacy. In their draft "Framework for Information Literacy Standards for Higher Education," Gibson and Jacobson observe that "the increasingly hybridized, multi-modal nature of learning and scholarship require an expanded conception of information literacy learning and pedagogy beyond the mostly text-based focus of the Standards" (23).

In the following sections, I will offer some examples of graphics and discuss some ways that librarians can use them to improve the way we interact with colleagues, patrons, and learners.

\section{Infodoodles, Infographics and Concept Maps}

\section{Infodoodles}

Our work frequently involves collaborating on projects with colleagues. Too often this collaboration relies almost exclusively on verbal and written communication. In her recent book, The Doodle Revolution, Brown argues that "doodling encourages innovation and creative thought by igniting various parts of the mind" (28). If doodling is "thinking in disguise," infodoodling is its more advanced partner-a method that relies on a combination of words, images, and shapes to enrich thinking $(2,65)$. Using whatever means are available at the time, ("markers, sticky notes, digital tablets, software, notebook paper, game pieces"), infodoodlers can work alone or together to brainstorm ideas, create project plans, solve specific challenges, visualize relations among various elements, or explore ideas and objectives (65).

\section{Infographics}

Infographics are underutilized on library websites. By using a combination of words, images, and shapes, we can arrange and present information in a concise and easy-tounderstand way. Visual design apps such as Piktochart and Infochart provide templates to simplify the creation of infographics.

\section{Concept Maps}

Concept maps are infographics that are surprisingly versatile. In "Teaching, Designing, and Organizing: Concept Mapping for Librarians," Colosimo and Fitzgibbons explore a variety of ways that graphical representations of relationships between concepts can be used as a personal or collaborative medium for information. These maps impose structure and organization on disparate ideas. As an organizational tool, concept maps can be used to plan projects, presentations, and entire courses. They help keep us focused on goals and objectives. They also strip away unnecessary detail so that we can see the essence of an idea. As Colosimo and Fitzgibbons observe, concept maps lend themselves to curriculum design, project planning, brainstorming sessions, and research project plans. They can be used to generate keywords and narrow down 
essay topics. In the classroom, concept maps are an interactive tool that can engage learners. For example, Figure 1 demonstrates using concepts maps to explore the various facets of a broad topic. They are particularly useful for explaining complex ideas in an easy-to-understand way.

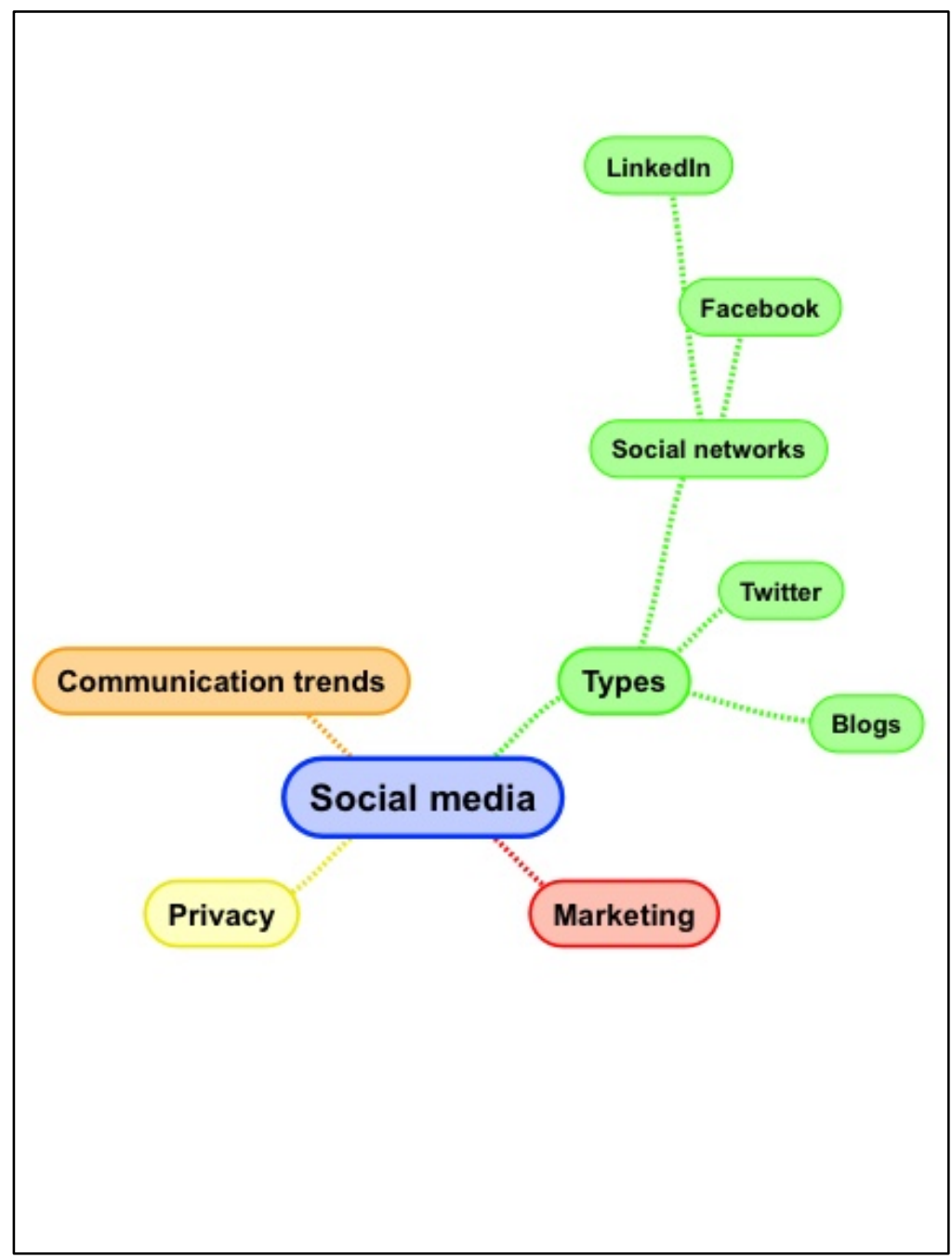

Figure 1. Use concept maps to narrow down a topic.

\section{Presentations}

Whether working with PowerPoint, Prezi, Keynote, or another program, we often use presentation software as a teaching tool. But all too often presentations fail to engage learners. Presenters frequently overuse the bullet-points template, and rely on bulleted lists as their teleprompter. Not only are most presentations text-heavy, but each slide within them is often crammed with too many words. As Duarte observes, the default template often produces a "slidument," or slide containing over 75 words $(7,144)$. Graphics, as Figure 2 shows, instantly convey abstract ideas in a concise and powerful way. 
In preparing slides, presenters should remember:

- Less is always more in a presentation; know what to omit so that what remains stands out.

- The principle of performance load: "The greater the effort to accomplish a task, the less likely the task will be accomplished successively" (Lidwell, Holden, and Butler 148).

- Reduce cognitive load by eliminating unnecessary words whenever possible.

- Do not be afraid of white space; it is "a powerful tool for directing the eye" (Reynolds 21).

\section{Engaging with scholarly research}

- Be active by note-taking

- Paraphrase essential ideas

- Focus on what is relevant to your research question

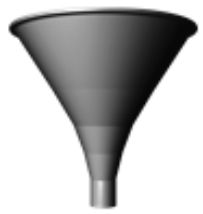

Figure 2. Use graphics to convey abstract ideas.

\section{Additional Tips for Employing Visual Communication in Presentations}

- Consider turning your words into graphics by placing them in concept maps or charts.

- Use an option such as the "smart art" feature in PowerPoint to place words inside shapes, making visual their relationships with other words.

- Keep in mind the principle of salience: "Attention is drawn to large perceptible differences" (Kosslyn 7). Keep in mind the following:

o Slides that are all the same do not get noticed.

o Use colour to highlight key points; never use it for decorative touches.

o Learners will remember those points if they stand out in some visual way.

Marketers and graphic designers have made it their business to study universal principles of design. They know that presentation slides are "a glance media more closely related to billboards than anything else" and that their message needs to be processed in less than three seconds (Duarte 140). From his research on multimedia instruction, Mayer has developed a set of guiding principles: 
- People learn better from words and pictures, than from words by themselves.

- Words and pictures work best when presented near each other rather than farther away, and simultaneously rather than successively.

- People learn best when extraneous words and pictures are eliminated.

- Use a mixture of essential keywords and content-related images.

- Never add images for purely decorative value.

An easy way to incorporate these ideas is to start with a pertinent picture or photograph, one large enough to cover the entire slide. Choose the right size, and avoid expanding a smaller image. Place text on a box of solid or semi-transparent colour to highlight the message you want to convey (Reynolds 54). See Figure 3 for an example.

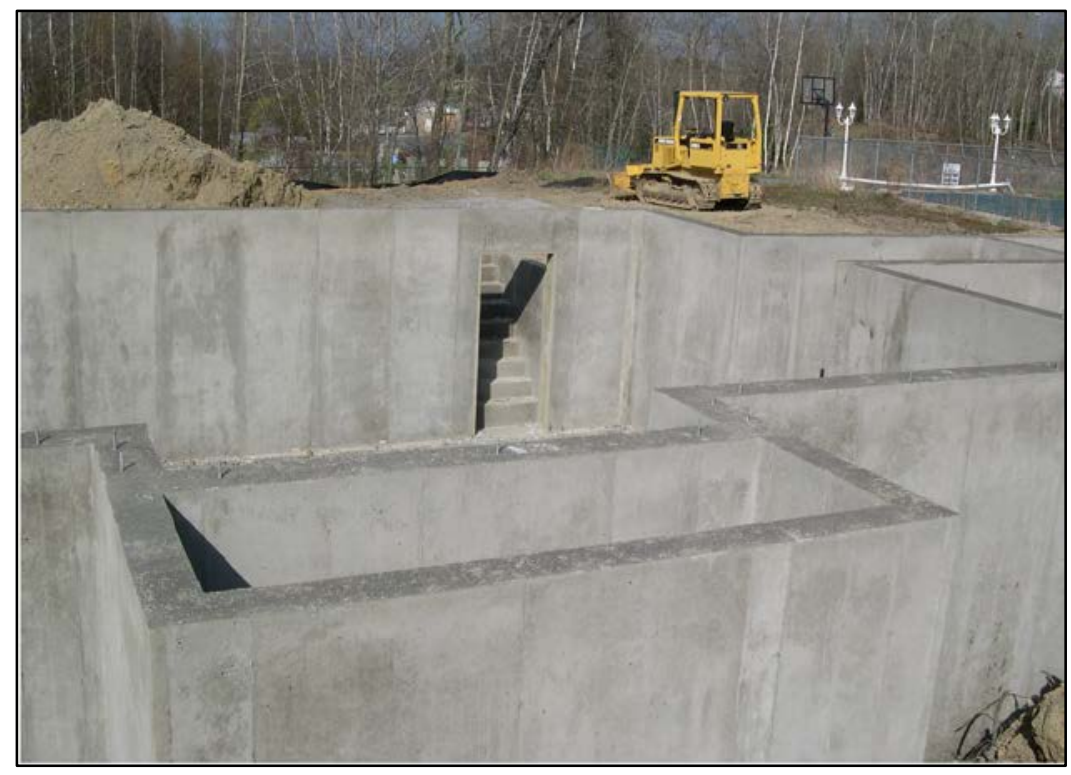

Figure 3. Use full-page graphics for emphasis.

Image Source: WTF Formwork, Basement egress steps, Wikimedia Commons, CC BY-SA 3.0

\section{Webpages}

Librarians increasingly communicate with users through websites. We can improve the way we do this by paying attention to the advice of web usability experts. They point out that the way most people design web pages is the opposite of the way users read them. After conducting numerous usability studies, Krug has observed:

When we're creating sites, we act as though people are going to pore over each page, reading our finely crafted text... What they actually do most of the time (if we're lucky) is glance at each new page, scan some of the text, and click on the first link that catches their interest or vaguely resembles the thing they're looking for. There are usually large parts of the page that they don't even look at. (28) 
Jakob Nielsen has identified an "F" pattern to screen reading. Users read in this Fshaped area, ignoring the rest of the page. Nielsen points out that large chunks of text create a negative visual impact. He advises website creators to eliminate dense text by making ample use of headings, subheadings, and bullet points. See Figure 4 for an example of this type of writing. Pertinent photographs, images, charts, concept maps, and white space will attract readers and improve communication.

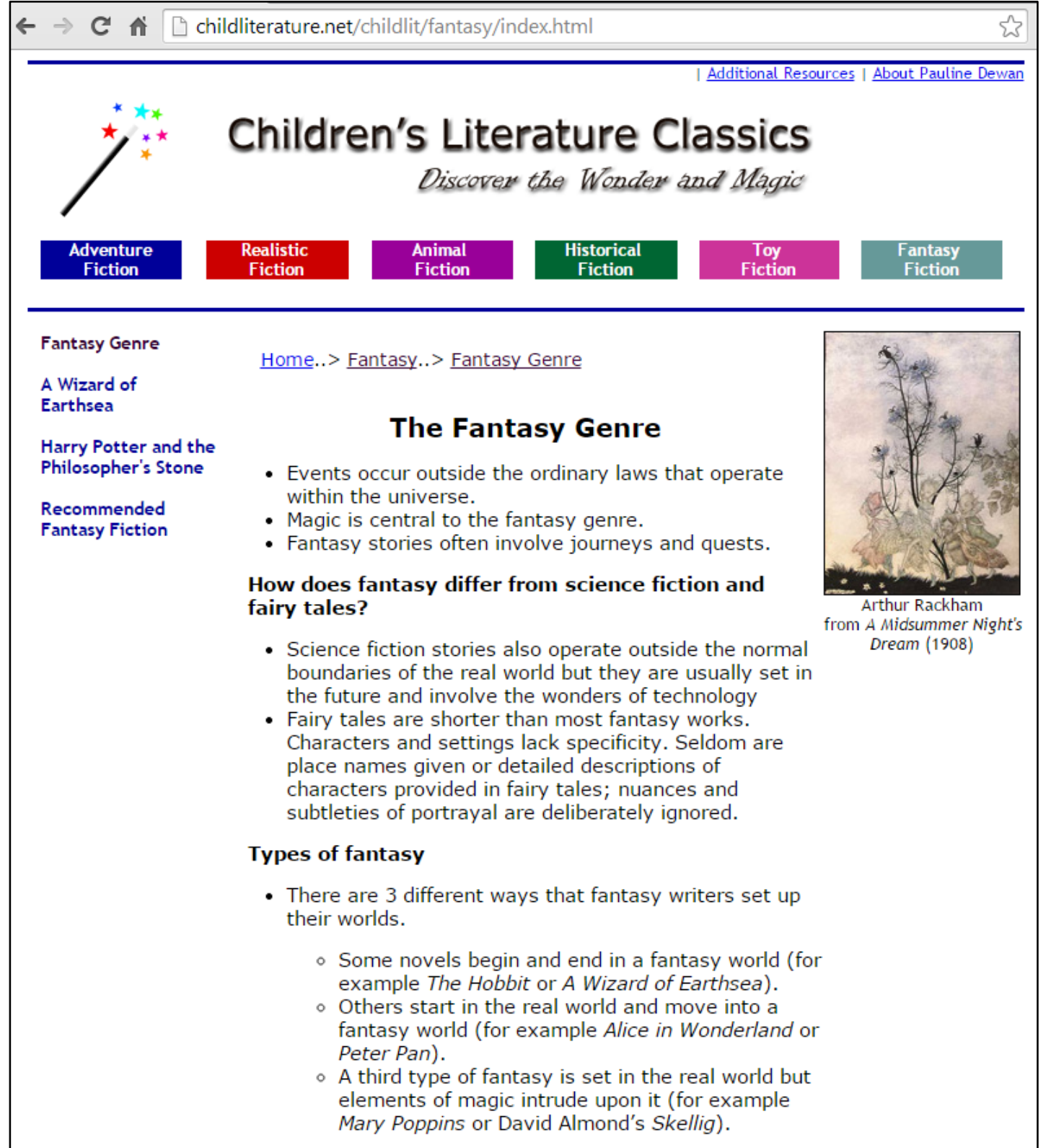

Figure 4. Use subheadings, bullets and graphics on a website.

Consider using Pinterest, the popular and ever-expanding visual discovery tool. Launched in 2010, and used by millions of "pinners," Pinterest can attract users in a variety of ways. For example, promote books by depicting book covers rather than listing their titles. Libraries are filled with collections of resources, and there is no better 
way of showcasing them than with Pinterest. Use it to document history, advertise events and services, upload posters, or track the progress of library renovations. Create your own Pinterest board to collect and share promising ideas. Never underestimate the power of visuals to engage and inspire users.

When trying to teach something, consider creating a video rather than a text-based tutorial. Upload videos to YouTube as well as your library website. Screencast videos allow instructors to demonstrate steps in a process in a much more effective manner than explaining the process in words. And according to Mayer, students learn best from videos when narration rather than on-screen text accompanies the visuals.

There is nothing inherently inferior about text, but our over-reliance on it and underutilization of graphics can lead to mediocre results. We live in an increasingly pictorial world, a development that we should embrace. If the twenty-first century individual prefers billboards over text-driven discourses, then we should "design great billboards" (Krug 41). Librarians are in the business of information, and the best way to communicate information is to use the full range of tools available to us.

\section{Works Cited}

ACRL. "ACRL Visual Literacy Competency Standards for Higher Education." 2011. Web. <http://www.ala.org/acrl/standards/visualliteracy>.

Apkon, Stephen. The Age of the Image: Redefining Literacy in A World of Screens. New York: Stephen Apkon, 2013. Print.

Brown, Sunni. The Doodle Revolution: Unlock the Power to Think Differently. New York: Portfolio/Penguin, 2014. Print.

Colosimo, April, and Megan Fitzgibbons. "Teaching, Designing, and Organizing: Concept Mapping for Librarians." Partnership: The Canadian Journal of Library and Information Practice and Research 7.1 (2012): n. pag. Web. 15 Dec. 2015. $<$ https://journal.lib.uoguelph.ca/index.php/perj/article/view/1800\#.VEIZxPnF W8>.

Davies, Duncan, Diana Bathurst, and Robin Bathurst. The Telling Image: The Changing Balance between Pictures and Words in a Technological Age. Oxford: Clarendon Press, 1990. Print.

Duarte, Nancy. Slide:ology: The Art and Science of Creating Great Presentations. Beijing: O'Reilly, 2008. Print.

Gibson, Craig and Trudi E. Jacobson. "Framework for Information Literacy for Higher Education. Draft 2." ACRL. June 2014. Web. <http://acrl.ala.org/ilstandards/wpcontent/uploads/2014/02/Framework-for-IL-for-HE-Draft-2.pdf>. 
Hansen, Kirsten, Gillian Nowlan, \& Christina Winter. "Pinterest as a Tool: Applications in Academic Libraries and Higher Education." Partnership: the Canadian Journal of Library and Information Practice and Research, 7.2 (2012): n. pag. Web. $<$ http://davinci.lib.uoguelph.ca/index.php/peri/article/view/2011\#.VMG8Qd5bzww>.

Harp, Shannon F., and Richard E. Meyer. "The Role of Interest in Learning from Scientific Text and Illustrations: On the Distinction Between Emotional Interest and Cognitive Interest." Journal of Educational Psychology 89.1 (1997): 92-102. Education Source. Web.

Kosslyn, Stephen M. Clear and to the Point: 8 Psychological Principles for Compelling PowerPoint Presentations. Oxford: Oxford UP, 2007. Print.

Krug, Steve. Don't Make Me Think Revised: A Common Sense Approach to Web and Mobile Usability. $2^{\text {nd }}$ ed. Berkeley: New Riders, 2014. Print.

Levie, W. Howard, and Lentz, Richard. "Effects of Text Illustrations: A Review of the Research." ECTJ 30.4 (1982): 195-232. Education Source. Web. 15 Dec. 2015.

Lidwell, William, Kristian Holden, and Jill Butler. Universal Principles of Design: 100 Ways to Enhance Usability, Influence Perceptions, Increase Appeal, Make Better Design Decisions, and Teach Through Design. Beverly, MA: Rockfort, 2003. Print.

Mayer, Richard E. Multimedia Learning. $2^{\text {nd }}$ ed. Cambridge: Cambridge UP, 2009. Print.

Nielsen, Jakob. "F-Shaped Pattern for Reading Web Content." 17 April 2006. Web. 15 Dec. 2015. <http://www.nngroup.com/articles/f-shaped-pattern-reading-webcontent/>.

OCLC. Perceptions of Libraries 2010: Context and Community. 2011. Web. 15 Dec. 2015. <http://oclc.org/reports/2010perceptions.en.html>.

Paivio, Allan. Mental Representations: A Dual Coding Approach. New York: Oxford UP, 1986. Print.

Reed, Stephen K. Thinking Visually. New York: Psychology Press, 2010. Print.

Seppäanen, Janne. The Power of the Gaze: An Introduction to Visual Literacy. Trans. Aijaleena and Kris Clarke. New York: Peter Lang, 2006. Print.

Reynolds, Garr. PresentationZen Design: Simple Design Principles and Techniques to Enhance Your Presentations. Berkeley: New Riders, 2010. Print. 


\section{Further Reading}

Garr, Reynolds. Presentation Zen: Simple Ideas on Presentation Design and Delivery. Berkeley, CA: New Riders, 2008. Print.

Nielsen, Jakob. "How Users Read on the Web." 1 October 1997. Web. 15 Dec. 2015. <http://www.nngroup.com/articles/how-users-read-on-the-web/>.

Nielsen, Jakob. "Top 10 Mistakes in Web Design." 1 January 2011. Web. 15 Dec. 2015. $<$ http://www.nngroup.com/articles/top-10-mistakes-web-design/>.

Roam, Dan. The Back of the Napkin: Solving Problems and Selling Ideas with Pictures. Toronto: Portfolio, 2008.

Thornton, Elaine. "Is Your Academic Library Pinning? Academic Libraries and Pinterest." Journal of Web Librarianship 6.3 (2012): 164-75.

Weissman, Jerry. Winning Strategies for Power Presentations: Jerry Weissman Delivers Lessons from the World's Best Presenters. Upper Saddle River, NJ: 2013. Print. 